\title{
Solusi Penuntasan Akar Konflik Sara: Belajar dari Kasus Konflik Muslim-Buddhis di Tanjungbalai Medan Tahun 2016
}

\author{
Moh Rosyid ${ }^{1 *}$ \\ ${ }^{1}$ IAIN Kudus, Indonesia
}

\begin{abstract}
Abstrak: Data dalam artikel ini berasal dari laporan media online dan cetak serta publikasi lain tentang konflik yang terjadi di Tanjungbalai. Data dianalisis dengan menggunakan metode kualitatif untuk memahami bentuk konflik yang terjadi serta mencari jalan bagi resolusi konflik. Konflik dengan latar belakang agama dan etnik seringkali muncul di Indonesia, diantaranya 29 Juli 2016 di Tanjungbalai, Sumatera. Kerusuhan yang terjaid seringkali mengakibatkan kerugian materi dan nonmateriil, sehingga diperlukan usaha-usaha dari berbagai pihak untuk mencegahnya. Cara yang bisa ditempuh diantaranya: menumbuhkan kembali semangat pluralisme di antara pemeluk agama yang berbeda, membangun dialog antar umat beragama, serta penegakan hukum. Dalam kasus Tanjungbalai, delapan terdakwa dihukum penjara antara 1 bulan 18 hari hingga 2 bulan 18 hari. Menurut sebagian orang hukuman ini tidak adil jika dibandingkan dengan kerusakan yang terjadi di wihara karena kerusuhan itu serta dampak sosial yang terjadi.
\end{abstract}

Kata Kunci: konflik, resolusi, toleransi

\begin{abstract}
This article based on report published in online and printed media and other publications. Using descriptive qualitative method, the data are analyzed in order to understand the pattern of conflict and finding a way for conflict resolution.Religious-based and ethnic-based riots are continuously happen in Indonesia. One of those occurred on July 29, 2016 in the city of Tanjungbalai Sumatra. Riots cause material and non material losses so that efforts are required to prevent it. Those efforts may be: enhancing pluralism among religious people in order to reduce conflict, opening dialogue between people from different religious or ethnic background, and law enforcement. In the case of Tanjung Balai, eight perpetrators were sentence to jail around 1 month 18 days up to 2 months 18 days. Some people consider this decision is unjust compared to the material of the vihara (Buddhist temple) and non material loss i.e. social tension among the society.
\end{abstract}

Keywords: conflict, reconciliation, tolerance

\section{Pendahuluan}

Era global mempermudah masyarakat dalam mengakses informasi dengan memanfaatkan perangkat lunak. Pemberitaan tentang konflik umat beragama pun mudah diakses. Bila demikian, tidak bijaksana bila penuntasan kasus kerusuhan dalam aspek hukum tidak selesai dan tidak adil karena akan berpeluang terjadi lagi hal serupa. Calon pelaku pun tidak akan jera bila penegakan hukum tak adil. Sebut saja, kasus konflik agama di Tolikara Papua tahun 2015 dan Singkil Aceh belum tuntas penegakan hukumnya, disusul kasus di Tanjungbalai Medan 2016.

\footnotetext{
${ }^{*}$ Corresponding Author: Moh Rasyid (mrosyid72@yahoo.co.id). IAIN Kudus, Indonesia p-ISSN 2303-2952; e-ISSN 2622-8491 http://jurnal.radenfatah.ac.id/index.php/intelektualita
} 
Kota Tanjungbalai, Asahan, Sumatera Utara hari jadinya diperingati setiap 27 Desember. Dalam catatan sejarah, hal ini berpijak pada pengukuhan raja pertamanya Sultan Abdul Jalil pada tanggal tersebut di Kampung Tanjung 27 Desember 1620 M. Kampung itu diawali adanya bangunan balai yang berdekatan dengan Bandar yang saat itu masih sederhana. Wilayah Tanjungbalai semula sebuah kampung di sekitar Ujung Tanjung di Muara Sungai Silau dan aliran Sungai Asahan. Tempat itu kemudian diberi nama Kampung Tanjungbalai. Dengan dibukanya perkebunan di Sumatera Timur, seperti Asahan maka Tanjungbalai (berada di tepi Sungai Asahan, sungai terpanjang di Sumatera) sebagai pelabuhan yang kian ramai. Banyaknya orang singgah sehingga makin ramai hingga kini. Dengan demikian, Kota Tanjungbalai merupakan kota tua di Muara Sungai Asahan di Sungai Silau yang berdekatan dengan Selat Malaka Asahan, Langkat, Bilah, dan Kota Pinang. Konflik itu sebagai penyebab berakhirnya Kesultanan Melayu di Sumatera Timur.

Pembukaan perkebunan besar di sekitar Kabupaten Asahan menjadikan Tanjungbalai menjadi tujuan merantau berbagai etnis. Gelombang berikutnya bersamaan dengan dibukanya rel kereta api Medan-TanjungbalaiRantau Prapat dan berdirinya Deli Spoorweg Matschappij tahun 1883. Tahun 1980 Tanjungbalai sebagai kota terpadat penduduknya se-Asia Tenggara. Sumatera Utara ibu kota provinsinya di Kota Medan merupakan wilayah yang memiliki tidak kurang 33 kabupaten/kota, 419 pulau, 12 suku yakni Melayu, beberapa rumpun Batak, yakni Karo, Toba, Mandailing, Angkola, Simalungun, dan Pakpak. Ada juga Nias, Minangkabau, Aceh, Jawa, dan Tionghoa. Ada delapan etnis utama di Sumut, yakni Batak (Karo, Simalungun, Pesisir, Mandailing, Pakpak), Melayu, dan Nias. Adapun etnis pendatang adalah Jawa dan Tionghoa, etnis
Batak Karo mewujudkan Gereja Batak Karo Protestan (GBKP), etnis Simalungun dengan gerejanya yang terkenal Gereja Kristen Protestan Simalungun (GKPS), etnis Pesisir di wilayah Pantai Barat Sumut, yakni Barus hingga Natal, etnis Mandailing ada di Kabupaten Tapanuli Selatan dan Kabupaten Mandailing Natal. Etnis Mandailing lainnya adalah Angkola Sipirok dan Padanglawas, etnis Pakpak di Kabupaten Dairi, etnis Nias terhimpun dalam gereja Banua Niho Keriso Protestan (BNKP) (Yusuf, 2013). Berdasarkan data BPS Tanjungbalai tahun 2010, etnis Batak sebanyak 42 persen, Jawa 17 persen, Melayu 15,4 persen, Minang 3,58 persen, Aceh 1,11 persen, lainlain 20,28 persen. Pemeluk Islam 83,30 persen, Kristen 8,44 persen, Katolik 0,76 persen, Hindu 0,04 persen, Buddha 7,44 persen, dan Konghucu 0 persen. Dengan luas wilayah $60,52 \mathrm{~km}$, jumlah penduduk tahun 2015 ada 154.445 jiwa terdiri Suku Batak Toba, Jawa, Melayu, Batak Karo, Batak Simalungun, Tionghoa, dsb. Sekitar 90 persen muslim, sisanya Kristen, Buddha, dan agama lain. Pekerjaan warga mayoritas sebagai nelayan. Sebelum tahun 1965, Kota Tanjungbalai satusatunya kota di Sumatera setiap bulan mementaskan Opera Beijing di panggung terbuka selama sebulan penuh oleh warga menyebut 'wayang Cino'.

Kerusuhan Mei 1998 di Tanjungbalai merupakan awal runtuhnya mafia yang dibangun oleh Suwardi Salim alias Abie Besok yang dikenal sebagai penyelundup kelas kakap di Tanjungbalai yang kiprahnya meluas hingga di Aceh, Riau, dan Jambi. Mulai illegal loging yang diekspor ke Malaysia. Abie mampu melobi penguasa hingga pejabat di Jakarta. Abie membekingi etnis Tionghoa di Tanjungbalai. Abie akrab dengan $\mathrm{M}$. Kosasih tatkala menjadi Ketua Pemuda Pancasila Tanjungbalai. M. Kosasih mempunyai mitra dengan M. Rasyid Ridho, Edi Balon, dan Anwar 
Tembak. M. Kosasih menjabat sebagai Ketua Pemuda Pancasila digantikan M. Rasyid Ridho. Dalam perjalanannya, M. Kosasih lebih akrab dengan kelompok Felik Wijaya atau Aweng yang di dalamnya ada Zaharuddin (Ketua Pemuda Muslim Indonesia Sumut), Rorel Harahap (saat menjadi Wali Kota Tanjungbalai), Romaynoor (menjabat Ketua DPRD Tanjungbalai). Tatkala kerusuhan Mei 1998 dijadikan sebagai alat bagi orang yang menyimpan dendam dengan Abie Besok yang dekat dengan orang Cina di Tanjungbalai. Kerusuhan terjadi di Tanjungbalai berupa pembakaran ratusan rumah warga Tionghoa dan penjarahan toko milik warga Tionghoa. Peristiwa itu diawali ketika tiga anak penyemir sepatu di trotoar toko perabot rumah tangga milik orang Cina di Jalan Sisingamangaraja Tanjungbalai. Mereka diusir dengan ditendang sehingga mengadukan pada pengasuh pesantren Modern Al-Falah, Drs. H.Chairul Fuad (H. Buyung), cucu H.Tuan Tahir Abdullah ulama besar di Sumut. Buyung juga mantan anggota DPRD Tanjungbalai dan menjabat anggota DPRD Sumut. Ketiga anak penyemir dibawa Buyung ke DPRD Sumut untuk menyelesaikan persoalan kekerasan pada anak. Maka diadakan sidang terbatas untuk menengahi pesoalan 3 anak penyemir sepatu agar tak terjadi konflik SARA. Warga berdatangan ke gedung DPRD Tanjungbalai yang sasarannya pada M. Kosasih, anggota dewan yang dianggap dekat dengan Tionghoa. M. Kosasih diamankan oleh Komandan Pos TNI AL Kapten Teguh Widodo. Pendemo terbagi dua, ada yang tetap di gedung DPRD ada yang berada di dekat toko yang pemiliknya menendang 3 anak penyemir sepatu. Toko tersebut dikawal Pemuda Pancasila lengkap dengan pakaian lorengnya. Abie Besok dikawal Edi Balon, Anwar Tembak, dan M. Rasyid Ridho dan tukang pukulnya melakukan patroli di jalan-jalan Tanjungbalai dangan mobil jip willis bak terbuka dengan bersenjata api di tangan. Melihat aksi Pemuda Pancasila, masa makin beringas dan melempar rumah warga Tionghoa. Massa dikendalikan oleh TNI AL dari Korem Pematang Siantar dan Brimob. Pada 28 Mei 1998 masa yang melakukan penjarahan toko ditangkap polisi. Kiprah Abie Besok menurun drastis karena warga sudah berani melawan arogansinya. Abie Besok pun tak lagi mampu mencari simpati warga Tionghoa karena ia mengutip biaya pengamanan tapi tak mampu mengendalikan situasi keamanan Tionghoa di Tanjungbalai (Kompasiana, 2014). Presiden Jokowi mengajak bagi yang mayoritas mengayomi minoritas dan minoritas mengayomi mayoritas, semua saling bertoleransi. Kerusuhan itu jangan melebar dan jangan kembali terulang (Kompas, 2016).

Dengan paparan tersebut, permasalahannya adalah persoalan apakah yang belum tuntas penyelesaiannya sehingga memicu kerusuhan di Tanjung Balai tahun 2016? Tujuan riset ini untuk mengingatkan publik dan pemerintah bahwa tak tuntasnya penyelesaian koflik bernuansa SARA di Tanjung Balai rentan terulang kembali.

\section{Metode Penelitian}

Metode penelitian dalam naskah ini teknik pengumpulan data bersumber dari pustaka/referensi berupa pemberitaan media massa dan tulisan para ahli. Tahapan analisis data berupa pengolahan dan analisis deskriptif kualitatif. Mengolah data/memeriksa data pada seluruh data dari hasil pemberitaan dan literatur yang dianalisis untuk menarik simpulan penelitian. 


\section{Hasil Penelitian dan Pembahasan}

\section{Sisa Bara Konflik yang Belum Padam Prakerusuhan Juli 2016 di Tanjungbalai}

Pada awalnya, Gerakan Islam Bersatu (GIB) melakukan demonstrasi di Kantor DPRD Tanjung Balai dan Kantor Wali Kota pada 30 Mei dan 29 Juni 2010. Mereka mendesak pemerintah menurunkan patung yang tingginya 6 meter berada di lantai 4 Wihara Tri Ratna. Dalih penurunan, keberadaan patung tidak mencerminkan kesan islami di Kota Tanjungbalai dapat mengganggu keharmonisan di tengah masyarakat. Penyebab demonstrasi GIB, menurut analisis Irwansyah, pertama, jabatan Wali Kota Tanjungbalai periode yang kedua bagi Sutrisno akan berakhir dan anak Sutrisno berkeinginan mencalonkan diri sebagai Wali Kota Tanjungbalai. Di sisi lain, anggota DPRD Asahan, ia berasal dari Tanjungbalai ingin mencalonkan sebagai Wali Kota Tanjungbalai. Keberadaan sang anggota dewan kurang populer bila dibandingkan dengan kepopuleran putra Wali Kota Sutrisno, meski anggota dewan tersebut cucu dari tokoh besar di Tanjungbalai. Diduga, sang anggota dewan itulah yang mengembangkan isu patung Buddha untuk diturunkan dari lantai 4 di Wihara Tri Ratna. Aspek lain, dikesankan bahwa terjadi perubahan/pergantian bahwa semula Tanjungbalai dikenal sebagai "kota kerang" (simbol nelayan) atau Kota Melayu (simbol muslim) menjadi kota Cina dengan simbol wihara. Ketiga, fanatisme simbolik. Beberapa surat yang berhasil didokumentasikan Irwansyah sebelum terjadinya konflik Juli 2016 di Tanjungbalai (Irwansyah, 2013).

Pertama, tanggal 3 Juni 2010, surat dari FKUB Sumatera Utara Nomor 60.0-1/FKUBI/VI/2010 perihal himbauan kepada FKUB Kota Tanjungbalai dan masyarakat agar proaktif menangani kasus penurunan Patung Buddha
Amitabha dan mengajak masyarakat menjaga situasi tetap kondusif, tidak melakukan tindakan anarkhis dan menjaga perdamaian. Kedua, tanggal 8 Juni 2010, surat dari Dirjen Bimas Buddha Kementerian Agama Nomor: DJ.VI/3/BA.02/604/2010 ditujukan kepada Ketua Vihara Tri Ratna Kota Tanjungbalai. Inti surat, agar Patung Buddha Amithaba dipindahkan ke pelataran atau tempat lain yang terhormat. Ketiga, tanggal 12 Juni 2010 surat dari Yayasan Vihara Tri Ratna Nomor 05/YVTR-VI/2010 kepada Dirjen Bimas Buddha Kemenag RI. Surat berisi tanggapan penyesalan atas surat Dirjen Bimas Buddha yang meminta menurunkan patung, Dirjen agar meninjau ulang surat Nomor: DJ.VI/3/BA.02/604/2010 karena patung merupakan satu kesatuan dengan wihara; Keempat, tanggal 16 Juni 2010 surat dari Pengurus Daerah Majelis Buddhayana Indonesia Nomor 085/MDISumut/VI/2010 kepada Dirjen Bimas Buddha yang menyayangkan surat Dirjen Bimas Buddha karena tidak mendengar pendapat berbagai pihak khususnya umat Buddha di Kota Tanjungbalai; Kelima, 18 Juni 2010 Surat Wali Kota Tanjungbalai kepada Pengurus Wihara Tri Ratna, surat menindaklanjuti surat Dirjen Bimas Buddha Nomor: DJ.VI/3/BA.02/604/2010 tanggal 8 Juni 2010 agar Pengurus Wihara melaksanakan perintah Dirjen Bimas Buddha; Keenam, tanggal 23 Juni 2010 surat Dirjen Bimas Buddha kepada Ketua Wihara Tri Ratna dan Kakanwil Kemenag Sumut agar menyelesaikan masalah pemindahan patung yang diselesaikan secara kekeluargaan; Ketujuh, tanggal 28 Juni 2010 surat dari Gerakan Islam Bersatu (GIB) Nomor 014/GIB-TB/VI/2010 kepada Ketua DPRD Tanjungbalai perihal sejauhmana perkembangan tindak lanjut permasalahan patung Buddha; Kedelapan, tanggal 15 Juli 2010 surat MUI Kota Tanjungbalai Nomor 010/DP.11/S/VII/2010 perihal saran dan himbauan kepada Wali Kota Tanjungbalai atas unjuk rasa 
GIB ke Kantor DPRD Tanjungbalai pada 30 Mei dan 29 Juni 2010 yang keberatan terhadap letak Patung Buddha di atas lantai 4 wihara; Kesembilan, tanggal 30 September 2010 surat Wali Kota Tanjungbalai Nomor 100/18348/T-an/2010 perihal penyelesaian kesepakatan bersama permasalahan patung. Surat ditujukan pada Wakil Ketua DPRD, Kepala Kejaksaan Negeri, Kapolres, Dandim 0208 Asahan, Kemenag Kota, Ketua Forum Komunikasi Umat Beragama (FKUB), Ketum MUI, dan Ketua Yayasan Wihara Tri Ratna di Tanjungbalai; Kesepuluh, Wali Kota memprakarsai penandatanganan kesepakatan bersama tanggal 3 Agustus 2010 sebagai bagian tindak lanjut rakor Muspida (Wali Kota, Komisi A DPRD), dan GIB Rabu 28 Juli 2010. Rapat Wali Kota dengan Pengurus Wihara pada Senin, 2 Agustus 2010 disepakati pemindahan patung; Kesebelas, tanggal 30 September 2010 Surat Wali Kota Tanjungbalai Nomor 100/18349/T-an/2010 kepada Ketua Yayasan Wihara Tri Ratna perihal tindak lanjut kesepakatan bersama dan mempertanyakan belum dipindahkannya patung; Kedua belas, tanggal 23 Februari 2011 surat Wali Kota Tanjungbalai yang menindaklanjuti surat sebelumnya Nomor 100/18349/T-an/2010. Inti surat agar pemindahan patung segera dilaksanakan.

Di tengah bersitegang antara keinginan memindahkan patung Buddha bagi muslim Tanjungbalai dengan keinginan mempertahankan Patung Buddha setinggi 6 meter berdiri di lantai 4 wihara Tri Ratna, ada isu yang menyejukkan bagi muslim yakni akan dibangun masjid terapung yang berkapasitas 10.000 jamaah. Masjid rencananya berada di Muara Sungai Silau sebagai simbol kemegahan yang menggantikan kemegahan 'Balai' yang 'tenggelam' karena dibangunnya Wihara Tri Ratna. Wihara di jalan Asahan Kota Tanjungbalai itu menampung 2.000 umat seluas $1.432 \mathrm{~m}$, 4 lantai yang diresmikan 8 November 2009 berdasarkan
Ijin Mendirikan Bangunan (IMB) Wali Kota Tanjungbalai Nomor 648/237/K/2006 (Irwansyah, 2013). Selain faktor tersebut, benih kerusuhan diakibatkan penafsiran atau anggapan warga nonTionghoa atas penggunaan bahasa Tionghoa/Mandarin ragam Hokkian/Hokka/Hakka yang digunakan etnis Tiongoa di Tanjungbalai. Hal ini akibat ruang interaksi terbatas sehingga kerjasama sosial tidak terjadi. Seperti tidak bergabung bergotong royong antara etnis Tionghoa dengan Melayu Pribumi.

Hal lain yang ikut memicu kerenggangan sosial karena kesenjangan ekonomi antara Tionghoa dengan non-Tionghoa (Melayu dan lainnya) adalah banyaknya pemodal dengan kepemilikan kapal tongkang oleh etnis Tionghoa, sedangkan etnis lain perekonomiannya menyusut akibat menurunnya komoditas primodona, yakni kopra, kelapa, dan menurunnya hasil tangkapan ikan bagi nelayan. Kesenjangan ditambah dengan keberadaan Tanjungbalai sebagai wilayah perlintasan penyelundupan barang haram dari Singapura dan Malaysia. Pelaku (penyelundup) narkoba didominasi pihak yang berkantung tebal sehingga semakin menambah kesenjangan ekonomi.

\section{Upaya Rekonsiliasi}

Secara teoretik, tahapan konflik agar tidak berkelanjutan maka hal yang harus dilakukan secara bersama antara warga masyarakat dengan pemerintah adalah pencegahan, penanggulangan, rehabilitasi, dan rekonstruksi.

Pertama, Ketua Majelis Tinggi Agama Konghucu Indonesia (MAKIN) Kota Tanjungbalai, Asan Kamis 4 Agustus 2016 mendatangi Kantor DPRD Kota Tanjungbalai untuk beraudiensi terkait kerusuhan. Asan menyatakan, menyesal atas ulah seorang, kebersamaan ini pecah. Asan setuju bila 
Meliana diproses secara hukum. Pihaknya tak keberatan jika Meliana tak berdomisili lagi di Kota Tanjungbalai.

Kedua, rekonsiliasi ditandatangani Badan Komunikasi Pemuda dan Remaja Masjid Indonesia (BKPRMI), Forum Komunikasi Umat Buddha (FKUB), Forum Komunikasi antar Lembaga Adat (Forkala), Komite Nasional Pemuda Indonesia (KNPI), perwakilan etnis Tionghoa, Minang, tokoh agama, dan Forum Kebangsaan Tanjungbalai. Pernyataan sikap dibubuhi surat Pemkot Tanjungbalai tertulis: Kami mewakili seluruh unsur masyarakat Kota Tanjungbalai menyatakan (1) berperan secara pro-aktif dalam rangka menjaga keamanan, ketertiban, dan kerukunan umat beragama di Tanjungbalai, (2) menjadi contoh/teladan bagi seluruh jajaran/anggota masyarakat dalam upaya menjaga kerukunan antarumat beragama di Kota Tanjungbalai, (3) bersama menjaga sarana dan prasarana rumah ibadah dari gangguan pihak yang tidak bertanggung jawab di Kota Tanjungbalai, (4) bersedia menjadi penyampai informasi dan mengajak jajaran/anggota masyarakat mengenai pentingnya kerukunan antar-umat beragama di Kota Tanjungbalai, (5) mendukung proses penegakan hukum dalam upaya menjaga stabilitas keamanan dan ketertiban Kota Tanjungbalai, dan (6) bersama menjaga kondusifitas dan menolak segala bentuk anarkisme di Kota Tanjungbalai.

\section{Solusi Penuntasan Persoalan Tanjungbalai Perspektif Akademik}

Persaingan merupakan pintu masuk terjadinya konflik. Keberadaan konflik akan menjadi liar dan beringas, dapat pula konflik akan menjadi damai, tergantung pengelolaan atas konflik oleh pelaku konflik itu sendiri. Konflik mencuat menjadi kerusuhan massa bila ada gerakan sosial. Gerakan sosial menurut Putra (2006) tidak terlepas dari konteks ruang dan waktu yang mengiringi. Strateginya berkembang secara kreatif sesuai dengan kultur dan kondisi sosial politik yang muncul di suatu daerah. Persepsi seseorang terhadap konflik dilatarbelakangi oleh pengalaman dalam mengelola organisasi (kehidupan), tingkat pendidikan, dan pengaruh lingkungan sosial. Konflik pada awalnya dianggap sebagai suatu penyimpangan terhadap norma dan nilai yang berlaku di masyarakat. Dengan meningkatnya pengetahuan maka pandangan terhadap konflik mengalami perubahan. Pandangan tradisional terjadi pada dasawarsa 1930-1940-an. Konflik saat itu dipersepsikan sebagai peristiwa yang negatif dan identik dengan kekacauan, destruktif, dan dapat merugikan kelangsungan organisasi sehingga harus dicegah. Konflik dikonotasikan negatif (disfungsional). Pandangan interaksionis (pluralis) berusaha menstimulasi dan menciptakan konflik bila diketahui kelompok bersifat statis, apatis, dan tak tanggap terhadap perubahan dan tak inovatif. Kontribusi pandangan/pendekatan interaksionis adalah mendorong pemimpin untuk mempertahankan suatu tingkat konflik yang optimal yang dapat menciptakan inovasi, tanggap terhadap perubahan, kreatif dan cepat beradaptasi, dan kritis terhadap kegiatan intern organisasi (Wahyudi, 2008).

Menurut Fox, beberapa kemungkinan penyebab konflik adalah masalah tertentu, kebencian pribadi, pembelaan diri, perluasan dari satu persoalan, kurangnya komunikasi, budaya tertutup, ketegangan, meningkatnya keraguan, polarisasi, dan diskriminasi, kekerasan, serta gangguan (Fox, 2009). Apa pun dalihnya, konflik dan diskriminasi tak perlu terjadi di Indonesia karena alasan yang kokoh. Menurut Denny JA (2014), ada lima alasan untuk tidak terjadi diskriminasi di Indonesia, yakni ancaman kekerasan primordial, konsep ideal Indonesia, 
demokrasi memerlukan kebebasan sipil, peradaban modern adalah peradaban nondiskriminasi, dan Indonesia sebagai laboratorium negara muslim. Tetapi, bila telah terjadi konflik maka perlu upaya riil yang dapat menyelesaikan persoalan secara tuntas agar tidak terjadi konflik lagi. Upaya itu memerlukan peran mediator untuk memediasi dua kepentingan yang berbeda pemuncul konflik. Menurut Saifullah, digunakannya peran mediasi sebagai salah satu cara menyelesaikan sengketa dengan damai. Hal ini dilatarbelakangi kecenderungan manusia untuk menyelesaikan masalahnya dengan damai (win-win solution), proses berperkara di pengadilan yang lama dan biaya mahal, menumpuknya perkara di pengadilan, penyelesaian litigasi kadang menimbulkan masalah yang lebih panjang, dsb. Dengan demikian, ada dua cara penyelesaian konflik, yakni litigasi, jalur hukum oleh lembaga peradilan (court mandated mediation) berdasarkan Peraturan Mahkamah Agung Nomor 2 Tahun 2003 dan nonlitigasi/nonperadilan seperti lembaga mediasi, instansi pemerintah, advokat, lembaga pendidikan tinggi, dan sebagainya. Mediasi nonperadilan lazimnya menuju damai (Saifullah, 2007).

Memahami konflik, perlu pula langkah pemetaan konflik. Menurut Tolkhah (2007) yakni identitas para pihak yang terlibat, baik secara langsung maupun tak langsung, jenis relasi para pihak yang terlibat, berbagai kepentingan dan isu yang terlibat, dan pihak yang dapat didorong dalam melakukan resolusi konflik. Setelah terpetakan konfliknya, perlu pula memahami cara bernegosiasi dalam menyelesaikan konflik. Dalam bernegosiasi diperlukan prasyarat dari kedua belah pihak yang berkonflik, (1) membagi kepentingan bersama, bukan sepihak untuk saling mendapat keuntungan, (2) menyepakati prosedur negosiasi yang ditempuh, (3) sukarela dan saling dapat dipercaya, (4) kedua belah pihak mencari alternatif penyelesaian, dan (5) bila negosiasi belum disepakati maka penyelesaian dihentikan sementara dengan status quo (Darwis, 2007).

Mengatasi agar konflik umat beragama tak terulang, perlu menanamkan kesadaran pada setiap umat beragama yang direalisasikan dalam kehidupan berbekal pemahaman yang tepat atas perbedaan karena adanya dalih. Menurut Hamim, di era global masyarakat harus bersedia hidup di lingkungan sosial yang plural, melampaui sekat etnis, budaya, dan agama. Untuk menyelenggarakan kehidupan yang harmonis, dituntut mampu menghadapi realitas kebhinekaan (pluralism). Beberapa negara memiliki berbagai idiom politik yang bermakna sama atas makna kebhinekaan, Amerika dengan istilah meltingpot society, Kanada dengan sebutan multiculturalism community, India dengan nama composite society, sedangkan Indonesia dengan julukan Bhinneka Tunggal Ika. Dalam Islam, pluralisme merupakan dasar dari penciptaan (khilqoh) alam maka pluralisme tak berpotensi melahirkan konflik tapi berpotensi membentuk sebuah keseimbangan (equilibrium). Islam menetapkan syarat membuat keharmonisan dengan pengakuan terhadap komponen yang secara alamiah berbeda (diversity), adanya kesatuan dalam perbedaan (unity in diversity) (Hamim, 2007).

Menurut Sutirto (2000), pemicu kerusuhan etnis (Jawa-Cina di Solo tahun 1980 dan 1981) karena rasa benci sepihak, perilaku meniru, bujukan dan kekerasan, dan adanya pemimpin dalam kerusuhan. Kebencian orang Jawa terhadap Cina karena perlakuan istimewa diterima warga Cina dari birokrat Solo dalam segala hal sehingga menimbulkan kesenjangan sosial antara Cina-Jawa. Perilaku meniru pembobol, pembakar, penjarah secara sporadis terhadap rumah dan gedung milik etnis Cina dan milik pemerintah karena ada yang 
mengawali melakukannya. Propaganda (bujukan) orang dekat (saudara/teman) menjadi penyebab terjadinya kekerasan. Provokasi yang dilakukan oknum untuk mengajak pihak lain melakukan tindak kekerasan terjadi meskipun ajakannya tak sistematis/spontanitas. Lingkungan pemukiman yang memungkinkan warga multietnis yang berbeda bisa membaur (tidak tersegregasi secara sosial) menjadi faktor penting terciptanya komunikasi efektif. Persepsi stereotip dan jarak sosial tereliminasi bila munculnya pemahaman perilaku individu dari kelompok etnis. Hal ini ditentukan oleh kecakapan tiap etnis dalam berinteraksi. Ketidakadilan akan memicu konflik serupa. Penyelesaian kasus Tanjungbalai dianggap ada ketidakadilan karena Meliana sebagai pemicu konflik belum (saat itu) diberi sanksi apa pun dan pelaku kerusuhan divonis ringan dan semua beragama Islam.

Vonis tersebut ditetapkan Senin 23 Januari 2017 di PN Tanjungbalai. Selaku Hakim Ketua Ullina Marbun dengan dua hakim anggota, yakni Ahmad Rizal dan Forci Nilpa Darma, dengan jaksa Fakhrul Azmi Lubis dan Rawatan Manik. Adapun penasehat hukumnya Hendra Julianta dan Hasbin Prima Tanjung. Terdakwa dan penasehat hukum menerima vonis (Elshinta, 2017). Pada 21 Agustus 2018 Meliana divonis hakim PN Medan, Wahyu Prasetyo Wibowo, 18 bulan penjara karena terbukti menista agama Islam melanggar Pasal 156 A KUHP. Akibat kerusuhan 29 Juli 2016 menurut penulis ikut andil menghasilkan keputusan Setara Institute Jumat 7 Desember 2018 yang mempublikasikan indeks kota toleran pada 94 kota se-Indonesia. Kriterianya adanya regulasi yang toleran, pernyataan dan tindakan aparatur yang kondusif, tak satu pun terjadi pelanggaran kebebasan beragama, dan menata kelola keberagaman identitas keagamaan warganya dengan baik. Ada 10 kota tertoleran yakni
Singkawang, Salatiga, Pematang Siantar, Manado, Ambon, Bekasi, Kupang, Tomohon, Binjai, dan Surabaya. Adapun kota paling tak toleran adalah Tanjungbalai, Banda Aceh, Jakarta, Cilegon, Padang, Depok, Bogor, Makassar, Medan, dan Sabang.

Dalam catatan sejarah, kerusuhan rasial terjadi di Indonesia yang dikenal kerusuhan antiCina, antara lain. Pertama, tanggal 10 Mei 1963 di Bandung diawali keributan di Kampus ITB antara mahasiswa Cina dengan non-Cina. Kerusuhan menjalar hingga di Yogyakarta, Malang, Surabaya, dan Medan. Pada Desember 1966 sekolah Tionghoa di Indonesia ditutup dan tahun 1967 koran berbahasa Tionghoa ditutup pemerintah. Kedua, tanggal 31 Desember 1972 terjadi keributan antara etnis Tionghoa dengan Arab yang diawali perkelahian yang berakhir tewasnya orang Cina. Ketiga, tanggal 27 Juni 1973 sekelompok pemuda menghancurkan toko Cina. Dalihnya, pemiliki toko menggunakan kertas bertuliskan huruf Arab sebagai pembungkus dagangan. Keempat, tanggal 5 Agustus 1973 di Bandung. Awalnya, serempetan gerobak dengan mobil (yang dikendarai orang Cina) yang berbuntut perkelahian. Kelima, April 1980 di Makassar. Suharti, pembantu rumah tangga di rumah warga Tionghoa yang meninggal. Gosip yang berkembang ia tewas karena dianiaya majikannya. Keenam, 20 November 1980 kerusuhan di Solo. Awalnya, perkelahian pelajar Sekolah Guru Olahraga, antara Pipit Supriyadi denagn Kicak (warga Tionghoa). Perkelahian itu meluas menjadi kerusuhan anti-Cina. Ketujuh, September 1986 di Surabaya beredar isu majikan (orang Cina) menganiaya pembantunya. Kedelapan, 24 November 1995 Yoe Sing Yung, pedagang kelontong yang sedang stres menyobek al-Quran hingga terjadi penghancuran toko milik orang Cina. Kesembilan, 14 Januari 1996 massa merusak toko Cina sebagai pelampiasan karena tak 
mampu membeli tiket pertunjukan musik Iwan Fals. Kesepuluh, 30 Januari 1997 di Rengasdengklok terjadi percekcokan antara orang Cina dengan pribumi dipicu karena orang Cina merasa terganggu suara beduk menjelang salat subuh. Kesebelas, 15 September 1997 terjadi kerusuhan yang dipicu pembacokan yang dilakukan Benny Kerre pada pribumi. Kedua belas, kerusuhan Mei 1998 di berbagai daerah. Kerusuhan itu terkendali bila terwujud toleransi.

\section{Mempertanyakan Esensi Toleransi}

Pemaknaan atas toleransi yang dipublikasikan pejabat pemerintah lazimnya dengan melihat bangunan dua tempat ibadah atau lebih yang berbeda agama dan berdampingan. Akan tetapi, realitasnya perlu didalami kebenarannya bahwa tempat ibadah beda agama yang berdekatan apakah cermin realitas umat lintas agamanya juga damai secara nyata? Beberapa contoh tempat ibadah yang berdampingan dan dianggap cermin toleransi antara lain, pertama, Masjid Istiqlal dan Gereja Katolik Katedral di Jakarta Pusat. Gereja Katedral dibangun Belanda tahun 1891, Masjid Istiqlal dibangun pemerintah RI yang diresmikan 22 Februari 1978. Kedua, Masjid Al-Muqorrobin dengan Gereja Masehi Injili Sangihe Talaud Mahanaim di Tanjung Priuk Jakarta Utara. Ketiga, Gereja Perhimpunan Injili Baptis (GPIB) Immanuel dan Masjid Agung Jami' di jantung alun-alun Kota Malang Jawa Timur. Gereja dibangun tahun 1861 dan masjid dibangun tahun 1875. Keempat, Kompleks Puja Mandala, yakni bangunan tempat ibadah lima umat beragama dalam satu kompleks, yakni masjid, gereja Katolik dan Kristen, wihara, dan pura di Bukit Kampial Bali. Kelima, Gereja GKL Joyodiningratan dan Masjid Al-Hikmah di Jalan Gatot Subroto Nomor 222 Solo. Idealnya, toleransi sejati bila terciptanya kehidupan umat segama dan atau lintas agama yang saling menyadari di tengah persamaan dan perbedaan teologi.

\section{Kesimpulan}

Media massa berperan besar dalam membuat suasana damai, tidak provokatif, memberitakan berdasarkan fakta secara utuh. Bila terjadi konflik, perlunya upaya rekonsiliasi oleh pihak-pihak yang harus dibekali pentingnya kesadaran bertoleransi. Satu hal utama bahwa tindakan preventif agar kerusuhan di Tanjungbalai tidak terjadi lagi adalah harus dilakukan (1) proses hukum mempertimbangkan dan memperhatikan serta menghormati HAM yang melekat pada para tersangka, (2) pemerintah pusat, pemerintah provinsi Sumatera Utara, Pemkot Tanjungbalai memutus mata rantai komunikasi yang berorientasi pada kebencian ras, etnis, dan agama, (3) mereintegrasi sosial antar-etnis dan antaragama pascakerusuhan. Reintegrasi melibatkan tokoh agama, tokoh masyarakat (togamas) Tanjungbalai agar kerusuhan tahun 1979, 1989, 1998, dan 2016 tidak terulang lagi, dan (4) memastikan jaminan rasa aman, nyaman, dan memastikan tidak terulangnya kembali peristiwa pada masa mendatang untuk dilaksanakan.

\section{Daftar Pustaka}

Abrar, Ana Nadhya. Tantangan dalam Mewujudkan Kesetaraan Gender dalam Pers di Indonesia. Jurnal Ilmu Sosial Ilmu Politik Fisipol UGM. Vol.7 N0.3: Yogyakarta. 2004.

Atmakusumah. Sebelas Tahun Perjalanan UU Pers. Kompas, 23 September 2010.

Darwis, Djamaluddin. Negosiasi dalam Mengelola Konflik Membangun Damai. IAIN Walisongo Mediation Center: Semarang. 2007.

Fox, Anne. Mengendalikan Konflik Tips, Tak-Tik, dan Teknik. Selasar Surabaya Publishing: Surabaya. 2009.

Habib, Achmad. Konflik antaretnik di Pedesaan Pasang Surut Hubungan Cina-Jawa. LKiS: 
Yogyakarta. 2004.

Hamim, Thoha, dkk. Konflik dalam Perspektif Komunitas Beragama di Indonesia dalam Resolusi Konflik Islam Indonesia. Lembaga Studi Agama dan Sosial IAIN Sunan Ampel Surabaya dengan LKiS: Yogyakarta. 2007.

Irwansyah. Potensi Keretakan Hubungan Sosial Muslim-Buddhis (Kasus Konflik Patung Buddha di Kota Tanjungbalai Sumatera Utara). Jurnal Analisa Balai Litbang Kemenag Semarang Vol. 20 Nomor 02 Desember 2013.

J.A, Denny. Menjadi Indonesia Tanpa Diskriminasi. Data, Teori, dan Solusi. Inspirasi.Co: Jakarta. 2014.

Kompasiana, 27 Mei 1998 Peristiwa Amuk Massa di Kota Tanjungbalai, 19 Mei 2014.

Putra, Fadillah, dkk. Gerakan Sosial Konsep, Strategi, Aktor, Hambatan dan Tantangan Gerakan Sosial di Indonesia. Averroes Press: Malang. 2006.

Rahardjo, Turnomo. Menghargai Perbedaan Kultural Mindfulness dalam Komunikasi Antaretnis. Pustaka Pelajar: Yogyakarta. 2005.

Sutirto, Tundjung W. Perwujudan Kesukubangsaan Kelompok Etnik Pendatang. Yayasan Pustaka Cakra: Surakarta. 2000.
Saifullah, Muhammad. Sejarah dan Perkembangan Mediasi di Indonesia dalam Mengelola Konflik Membangun Damai. IAIN Walisongo Mediation Center: Semarang. 2007.

Sugihartati, Rahma. Kerusuhan, Media Sosial, dan Literasi Masyarakat. Jawa Pos, 3 Agustus 2016.

Tolkhah. Pemetaan Konflik dalam Mengelola Konflik Membangun Damai. IAIN Walisongo Mediation Center: Semarang. 2007.

Wahyudi. Manajemen Konflik dalam Organisasi. Alfabeta: Bandung. 2008.

Witdarmono, H. Wartawan dan Saham. Kompas, 4 Desember 2010.

Qodir, Zuly. Kontestasi Penyiaran Agama di Ruang Publik: Relasi Kristen dan Islam di Kota Jayapura. Jurnal Harmoni Puslitbang Kehidupan Keagamaan Badan Litbang dan Diklat Kemenag RI. Vol.14, No.1, JanuariApril 2015.

Yusuf, Choirul Fuad. Konflik Bernuansa Agama Peta Konflik Berbagai Daerah di Indonesia 1997-2005. Puslitbang Lektur dan Khazanah Keagamaan Balitbang dan Diklat Kemenag RI. Jakarta. 2013. 